\title{
Cytologic and DNA-cytometric early diagnosis of oral cancer
}

\author{
Torsten W. Remmerbach ${ }^{\mathrm{a}, *}$, Horst Weidenbach ${ }^{\mathrm{b}}$, \\ Natalja Pomjanski ${ }^{\mathrm{c}}$, Kristiane Knops ${ }^{\mathrm{c}}$, \\ Stefanie Mathes ${ }^{\mathrm{c}}$, Alexander Hemprich ${ }^{\mathrm{a}}$ \\ and Alfred Böcking ${ }^{\mathrm{c}}$ \\ ${ }^{a}$ Department of Oral, Maxillofacial and Plastic \\ Surgery, University of Leipzig, Nürnberger Straße 57, \\ D-04103 Leipzig, Germany \\ ${ }^{\mathrm{b}}$ Institute of Pathology, University of Leipzig, \\ Liebigstraße 26, D-04103 Leipzig, Germany \\ ${ }^{\mathrm{c}}$ Institute of Cytopathology, Heinrich Heine \\ University, Moorenstraße 5, D-40225 Düsseldorf, \\ Germany
}

Received 23 January 2001

Accepted 19 April 2001

Objective. The aim of this prospective study was to report on the diagnostic accuracy of conventional oral exfoliative cytology taken from white-spotted, ulcerated or other suspicious oral lesions in our clinic. In addition we checked DNAimage cytometry as an adjuvant diagnostic tool. Our hypothesis is that DNA-aneuploidy is a sensitive and specific marker for the early identification of tumor cells in oral brushings. Study design. 251 cytological diagnoses obtained from exfoliative smears of 181 patients from macroscopically suspicious lesions of the oral mucosa and from clinically seemingly benign oral lesions which were exisiced for establishing histological diagnoses were compared with histological and/or clinical follow-ups of the respective patients. Additionally nuclear DNA-contents were measured after Feulgen restaining using a TV image analysis system. Results. Sensitivity of our cytological diagnosis on oral smears for the detection of cancer cells was $94.6 \%$, specificity $99.5 \%$, positive predictive value $98.1 \%$ and negative predictive value $98.5 \%$. DNA-aneuploidy was assumed if abnormal DNA-stemlines or cells with DNA-content greater 9c were observed. On this basis the prevalence of DNA-aneuploidy in smears of oral squamous cell carcinomas in situ or invasive carcinomas was $96.4 \%$. Sensitivity of DNA-aneuploidy in oral smears for the

*Corresponding author: Dr. Torsten W. Remmerbach. Tel.: +49 3419721 100; Fax:+49 3419721 109; E-mail: remmt@medizin.unileipzig.de. detection of cancer cells was $96.4 \%$, specificity $100 \%$, positive predictive value $100 \%$ and negative $99.0 \%$. The combination of both techniques increased the sensivity to $98.2 \%$, specificity to $100 \%$, positive predictive value to $100 \%$ and negative to $99.5 \%$. Conclusions. Brush cytology of all visible oral lesions, if they are clinically considered as suspicious for cancer, are an easily practicable, cheap, non-invasive, painless, safe and accurate screening method for detection of oral precancerous lesions, carcinoma in situ or invasive squamous cell carcinoma in all stages. We conclude that DNA-image cytometry is a very sensitive, highly specific and objective adjuvant tool for the early identification of neoplastic epithelial cells in oral smears.

Keywords: Oral cancer, oral exfoliative cytology, DNAaneuploidy, DNA-image cytometry, cancer screening, diagnostic accuracy

\section{Introduction}

Squamous cell carcinomas of the oral cavity are among the ten most common cancers in the world, accounting for approximately $3-5 \%$ of all malignancies [48]. In 1993 in Germany, approximately 4100 new cases in males and 1000 in females were encountered [42]. In spite of great surgical, chemo- and radiotherapeutical efforts the 5-year-survival-rate could not be decreased so far, being still less than 50\% [23, 38]. However oral cancer can be cured, if detected and treated early enough [45]. Up to now scalpel biopsy with histological assessment seems to be the only accepted method to definitely evaluate suspicious oral lesions. But most dentists do not have the proficiency to perform biopsies of oral lesions themselves and a few patients may be perilous (e.g., by medication with coumarone derivates) to suffer a scalpel biopsy. Furthermore literature shows insufficient inter- and intraindividual reproducibility of histological grading epithelial dysplasias and unequivocally identifying carcinoma in situ $[1,2]$.

One should furthermore emphasize the importance of an early diagnosis of oral cancers in order to reduce their unacceptably high morbidity and mortality. Yet, 
scalpel biopsies are not suitable as screening tool for the early identification of oral cancer because of their invasiveness. Alternatively a useful diagnostic screening procedure could be the obtainment of oral smears with subsequent cytologic examination. Smears from the uterine cervix are used worldwide since 50 years to successfully screen for dysplasias and early carcinomas at this site. With the help of this technique it was possible to decrease mortality of uterine carcinomas significantly $[28,36]$.

In the last few years interest in diagnostic cytopathology has newly emerged due to the application of adjunctive diagnostic methods. Using DNA-image cytometry on Feulgen (re-)stained smears, the cytometric equivalent of chromosomal aneuploidy, DNAaneuploidy, is an internationally accepted marker for neoplastic transformation of cells [10,29,30,32,33]. The cytometric analysis of nuclear DNA-content has previously been applied to oral neoplasia [47]. Schimming et al. [41] have evaluated the correlation of DNA distribution of oral squamous carcinomas to clinicopathologic features. They found a significantly higher $\mathrm{N}$ stage, frequency of metastasis and a lower survival rate with non-diploid tumors. Chatelain et al. [15] investigated the prognostic validity of a DNA-malignancy-grade, which was closely correlated with histologic grades of malignancy and revealed a strong association with the patients prognosis. Retrospective studies dealt with the malignant potential of dysplastic oral lesions evaluated by DNA-image cytometry [39]. Abdel-Salam et al. $[3,4]$ applied image cytometry to histological specimens from archived biopsy material to predict the malignant transformation of white lesions of the oral cavity (observation period of 1015 years) resulting in a $86 \%$ positive predictive value and $83 \%$ sensitivity. Doseva et al. [16] found that cytologic smears obtained from leukoplakia and lichen planus which later transformed to invasive carcinoma showed hypodiploid and hypertetraploid instead of diploid DNA distribution patterns.

The aim of this prospective study was to report on the diagnostic accuracy of conventional oral exfoliative cytology taken from white-spotted, ulcerated or other suspicious oral lesions in our clinic. In addition we checked the accuracy of DNA-image cytometry as an adjuvant diagnostic tool in oral exfoliative cytology on identical smears. Clinical and histological followup diagnoses were the "golden standard". Our hypothesis is that DNA-aneuploidy is a sensitive and specific marker for the early identification of cancer cells in oral smears.

\section{Materials and methods}

\subsection{Patient population}

The study population consisted of 251 cytological diagnoses on 1254 smears (at least four smears were prepared from each brushing) obtained from 181 patients (43\% females, 57\% males) with a mean age of 60 years (range 20-91 years), who had been referred for examination and treatment of oral lesions to the Department of Oral-Maxillofacial and Plastic Surgery, University of Leipzig, Germany between August 1997 and November 2000. The "golden standard" for the establishment of diagnostic accuracy was in 158 cases the (repeated) histology and in all cases the clinical follow up. Final diagnoses were: 56 histologically proven squamous cell carcinomas (Table 1), 83 leukoplakias (according to World Health Organization definition [49]) and 112 inflammatory or other seemingly benign hyperplastic oral lesions (Table 2).

\subsection{Clinical procedure}

Each patient was examined by an experienced member (T.W.R.) of the Department of Oral, Maxillofacial and Plastic Surgery. Before the cytologic brushings were performed, each patients medical history was documented and a thorough intraoral examination was conducted. After these evaluations, at least four cytological smears were obtained from the suspicious or pathological area using a Cytobrush cell collector (Cytobrush GT, Med-Scand Medical, Malmo, Sweden) [34]. The cytobrush was rolled on the glass slide

Table 1

Synopsis about tumor site and tumor spread of 56 patients with squamous cell carcinoma of the oral cavity

\begin{tabular}{lc}
\hline & Number of cases $(n=56)$ \\
\hline Tumor sites & 7 \\
floor of the mouth & 7 \\
floor of the mouth and tongue & 13 \\
tongue & 1 \\
lip & 14 \\
tonsil and palate & 6 \\
alveolar ridge & 8 \\
cheek & \\
Tumor spread & 3 \\
Tis & 13 \\
T1 & 13 \\
T2 & 10 \\
T3 & 12 \\
T4 & 5 \\
Tx & \\
\hline
\end{tabular}


Table 2

Synopsis about clinical or histological diagnoses and number of smears of all oral lesions $(n=251)$

\begin{tabular}{|c|c|c|c|c|}
\hline & Total & Histologically proven & Clinical follow-up & $\begin{array}{c}\text { Number of } \\
\text { smears }\end{array}$ \\
\hline Leukoplakia & 83 & 47 & 36 & 384 \\
\hline Lichen planus & 32 & 10 & 22 & 128 \\
\hline Lichen erosivus & 16 & 13 & 3 & 79 \\
\hline Lichen atrophicus & 1 & 1 & & 4 \\
\hline Pseudoempitheliomatous hyperplasia & 12 & 12 & & 48 \\
\hline Epulis granumotatosa & 2 & 2 & & 8 \\
\hline Desquamative gingivitis & 1 & 1 & & 4 \\
\hline Scar & 1 & 1 & & 4 \\
\hline Ulcus & 33 & 14 & 19 & 142 \\
\hline Glossitis rhombica mediana & 4 & & 4 & 21 \\
\hline Aphthous ulcer & 6 & & 6 & 31 \\
\hline Lingua plicata & 1 & & 1 & 4 \\
\hline Prostetic induced stomatitis & 1 & & 1 & 4 \\
\hline Papillomatosis & 1 & 1 & & 5 \\
\hline Lingual tonsil & 1 & & 1 & 6 \\
\hline Squamous cell carcinoma & 56 & 56 & & 382 \\
\hline
\end{tabular}

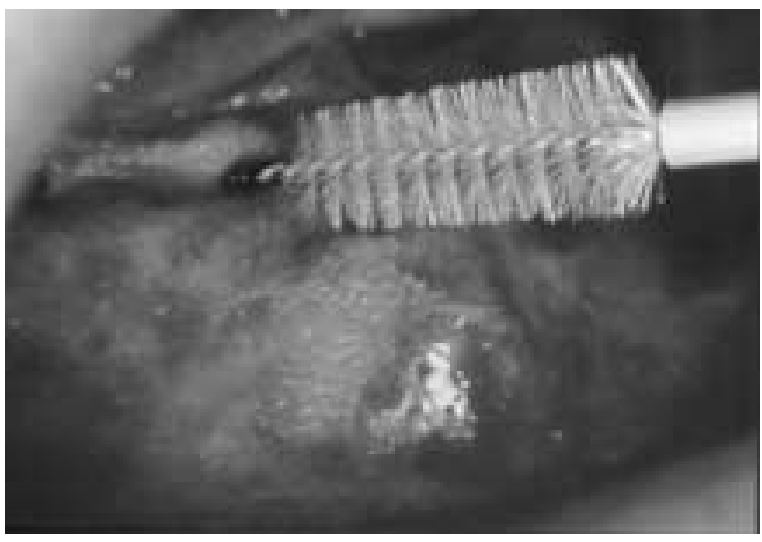

Fig. 1. Cell collector Cytobrush GT in situ (leukoplakia in the floor of the mouth).

and fixed immediately with Merckofix-spray (Merck, Darmstadt, Germany), a propanol and carbowax containing spray fixative (Fig. 1). If it seemed clinically indicated (i.e., in cases of suspicion of cancer or in benign lesions which could not be unequivocally assigned to a diagnosis), the obtainment of smears was followed by scalpel biopsy. Cytological and histological investigation had been carried out independently at different institutions.

\subsection{Staining and mode of interpretation}

The alcohol fixed slides were routinely stained according to Papanicolaou [27]. The specimens were evaluated according to generally accepted diagnostic criteria $[5,27]$ by an experienced cytotechnologist (K.K.) and in cytologically doubtful, suspicious or tumor cell positive slides additionally by an experienced cytopathologist (A.B.) as well. The following diagnostic criteria were the most important for the identification of tumor cells: hyperchromasia of nuclei, increased nuclear/cytoplasmic ratio, anisonucleosis and nuclear pleomorphism, irregularities of nuclear membranes, nuclear crowding and -moulding, chromatin clumping and irregularity of chromatin distribution. The following categories of cytological diagnoses were applied: "insufficient" for specimens without any or with exclusively autolytic cells, "tumor cell negative" for inconspicious, reactive or inflammatory cellular images, "doubtful" in cases with atypical cellular changes (e.g., with mild or moderate dyplasias), "suspicious for tumor cells" if only sparce abnormal cells (or servere dysplastic squamous cells) were seen or the diagnostic criteria for malignancy were only vague and "tumor cell positive" for smears containing unequivocal malignant cells [9].

\subsection{Feulgen staining [17]}

The slides of alcohol-fixed, Papanicolaou-stained, routine smears from mucosal brushings were uncovered in xylene. Subsequently they were destained and Feulgen stained in a temperature-controlled staining machine with Schiff's reagent. After rehydration in 
decreasing ethanol concentrations and refixation in buffered $10 \%$ formalin, $5 \mathrm{~N} \mathrm{HCl}$ for acid hydrolysis was applied at $27^{\circ} \mathrm{C}$ for one hour, followed by staining in Schiff's reagent (Merck, Darmstadt, Germany) for another hour, followed by rinsing in $\mathrm{SO}_{2}$ water and dehydration at increasing ethanol concentrations $[7,8,14]$. The slides were then covered with Entellan (Merck, Darmstadt, Germany) and stored in the dark.

\subsection{DNA-measurements}

The normal $2 \mathrm{c}$ reference value was established by measuring 30 cytologically normal squamous epithelial cells or lymphocytes in each slide as an internal reference (mean values of integrated optical densities (IOD)). CVs (=coefficient of variation) of reverence cells were below $5 \%$. No correction factor was applied. If present, three hundred atypical epithelial or carcinoma cells per specimen were measured interactively at random. Otherwise, only the available cells were measured: one (suspicious) case with 48 cells (=insufficient for DNA-cytometry); two cases with 51-100 measurable cells; four cases with 101150 cells; six cases with 151-200 cells; seven cases with 201-250 cells; seven cases with 251-300 cells and 30 cases $>300$ cells. No stemline interpretation of DNA-aneuploidy was performed if less than $50 \mathrm{ab}$ normal or atypical cells were contained. All inconspicious cases ("tumor cell negative") were measured using at least 30 reference cells and 300 analysing cells. The AutoCyte QUIC-DNA workstation (AutoCyte, Burlington, N.C., USA) was used for the measurements. It consists of a conventional light microscope (Axioplan 2, Zeiss, Jena, Germany) with a $40 \times$ objective, NA of 0.75; Köhler illumination was applied to reduce stray light and an interference filter $470 \mathrm{~nm}$, $\pm 10 \mathrm{~nm}$ half value width was used. A CCD black and white camera (VarioCam [Model CCIR] PCO Computer Optics, Kehlheim, Germany) with 572 lines resolution was adapted to the microscope. The images were analysed using a Pentium I processor with framegrabber (Kontron, Eching, Germany). The performance of the system meets the standards of the European Society for Analytical Cellular Pathology (ESACP) task force on standardization of diagnostic DNA-image cytometry $[11,18,21]$.

Segmentation was performed automatically on individual nuclei by grey level thresholding, taking the local background into consideration for each nucleus. The glare- and diffraction errors were corrected by software as proposed by Kindermann and Hilgers [26], glare at a rate of $8 \%$.

The data were interpreted using the analysis software of the system. We assumed DNA-aneuploidy if (1) the DNA index of the stemline was $<0.90>1.10$ or $<1.80>2.20$ or $<3.60>4.40$ or (2) cells $>9 \mathrm{c}$ occurred (9c exceeding events [9cEE]) [13]. A DNAstemline was defined as a frequency peak in a histogram accompanied by values at its twofold DNAcontent. It was defined interactively when the DNAhistograms were displayed on the screen by marking its minimum and maximum [31] (Figs 2-6).

\section{Results}

Of 251 technically sufficient brushings from suspicious oral lesions (Tables 1 and 2) a non-malignant diagnosis (=tumor cell negative) was made cytologically in 192 cases. Four cases were diagnosed as doubtful and eight as suspicious for tumor cells. The medical reports showed, that in 53 specimens of suspicious or tumor cell positive oral lesions of a malignant tumor was verified by subsequent histopathological diagnosis (correctly positive). In one case of histologically proven scquamous cell carcinoma the smears were cytologically diagnosed as negative for tumor cells. Reevaluation of the smears showed that a sampling error had occurred as no suspicious cells could be observed (false-negative). One case was cytologically diagnosed as positive for tumor cells, but histologically no tumor cells or dysplasias were seen (false-positive). In 192 cases without carcinomas in the clinical follow up cytology reported: "negative for tumor cells" (correctly negative).

Sensitivity of our cytological diagnosis in oral smears for the detection of cancer cells thus was $94.6 \%$, specificity for the detection of non neoplastic cells was $99.5 \%$, positive predictive value $98.1 \%$ and negative predictive value $98.5 \%$ (Table 3 ).

All cytologically tumor cell positive specimens showed DNA-aneuploidy, except one false-positive case that showed no DNA-aneuploidy. The correctness of DNA-cytometry was validated histologically. All cytologically tumor negative specimens were DNA-nonaneuploid. But one case was false-negative for cytology and DNA-cytometry, because a carcinoma was shown later histologically. It seems likely, that in this case a geographic error taking the smear has occurred, because the region where the lesion was located, was near the arcus palatoglossus and the obtainment of 


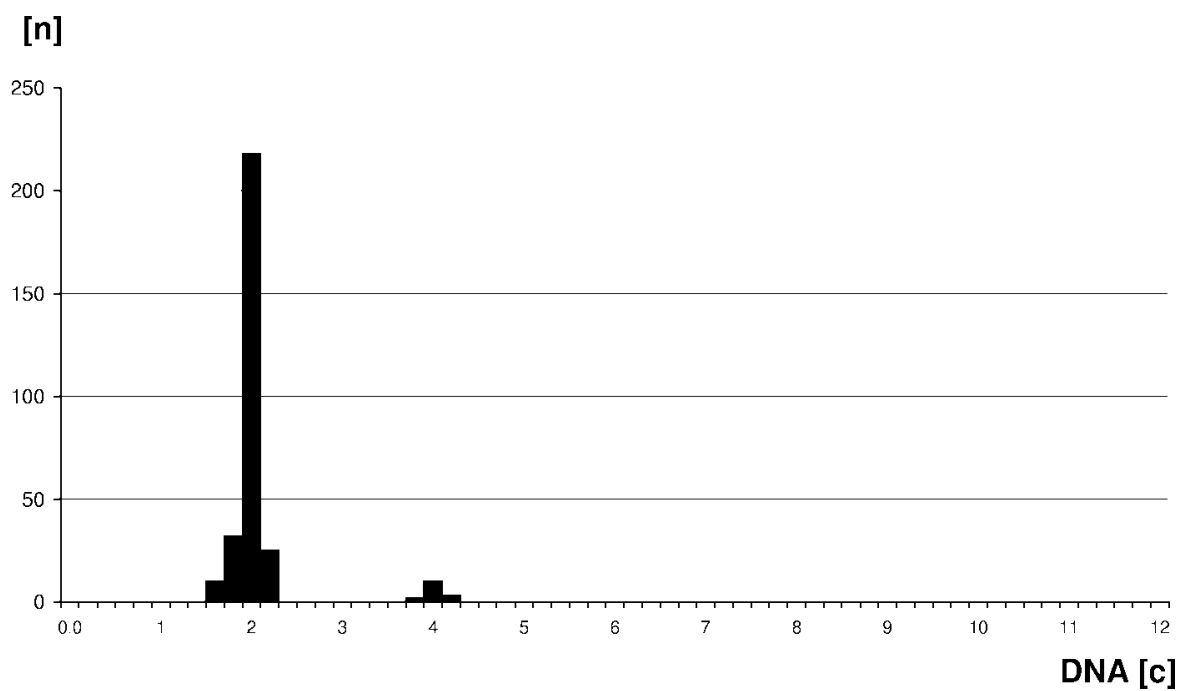

Fig. 2. DNA-histogram of a smear from a histologically proven hyperkeratosis without dysplasia, showing number of cells measured $(n)$ and their corresponding DNA-content (c) and a (normal) diploid stemline at 2.0c.

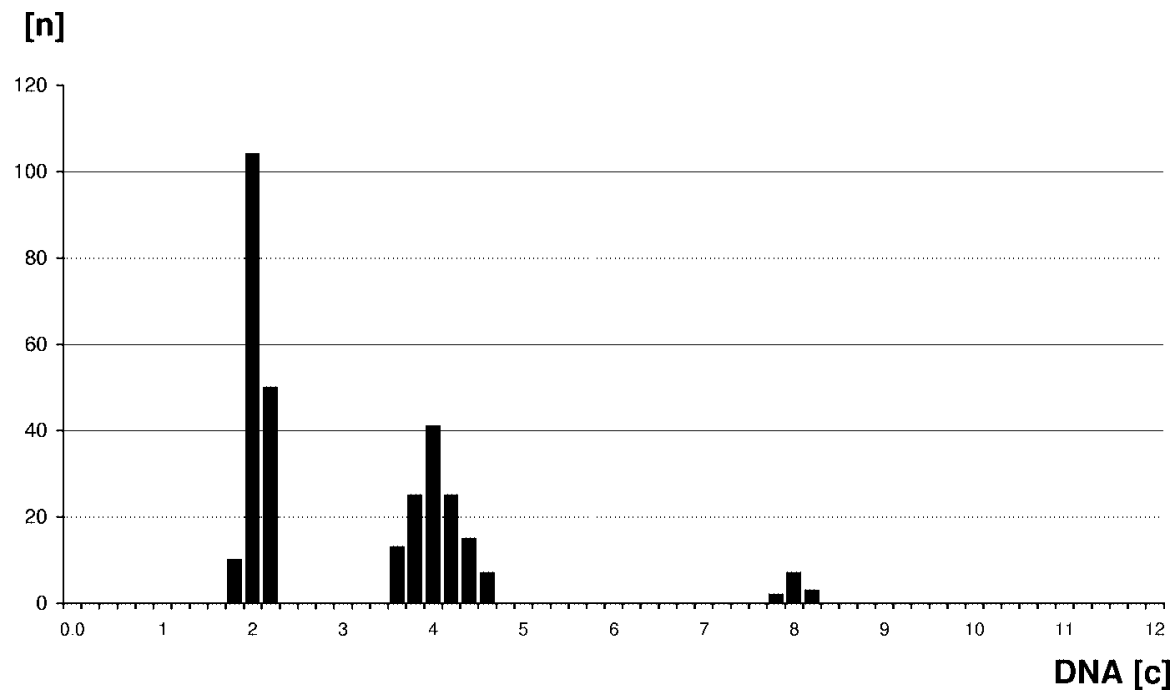

Fig. 3. DNA-histogram of a smear from a Lichen erosivus, showing (euploid) polyploid stemlines at 2.0c and 4.0c.

samples was very difficult, because the patient choked during the oral examination.

Four cases were cytologically "doubtful". Two of them were DNA-aneuploid, the other two were DNAnon-aneuploid. The scalpel biopsy showed squamous cell carcinomas in two cases with DNA-aneuploidy. The DNA-non-aneuploid specimens showed histologically no carcinoma. Eight cases were cytologically "suspicious", but six specimens were DNA-aneuploid. Squamous cell carcinomas were found histologically in all of them. One "suspicious" case was classified as insufficient for DNA-cytometry (not enough cells for measurement on the slide). Histologically a servere dysplasia (equivalent to carcinoma in situ) was shown.

Table 6 shows the frequencies of occurrence of different aspects of DNA-aneuploidy and the dependence of its detection by application of one or two different algorithms. It demonstrated that $9 \mathrm{cEE}$ was the most frequent single aspect of DNA-aneuploidy, followed by an abnormal stemline, and that the combined application of both algorithms significantly increased the rate of detection.

On this basis the prevalence of DNA-aneuploidy in smears of oral cancer or carcinomas in situ was $96.4 \%$. 


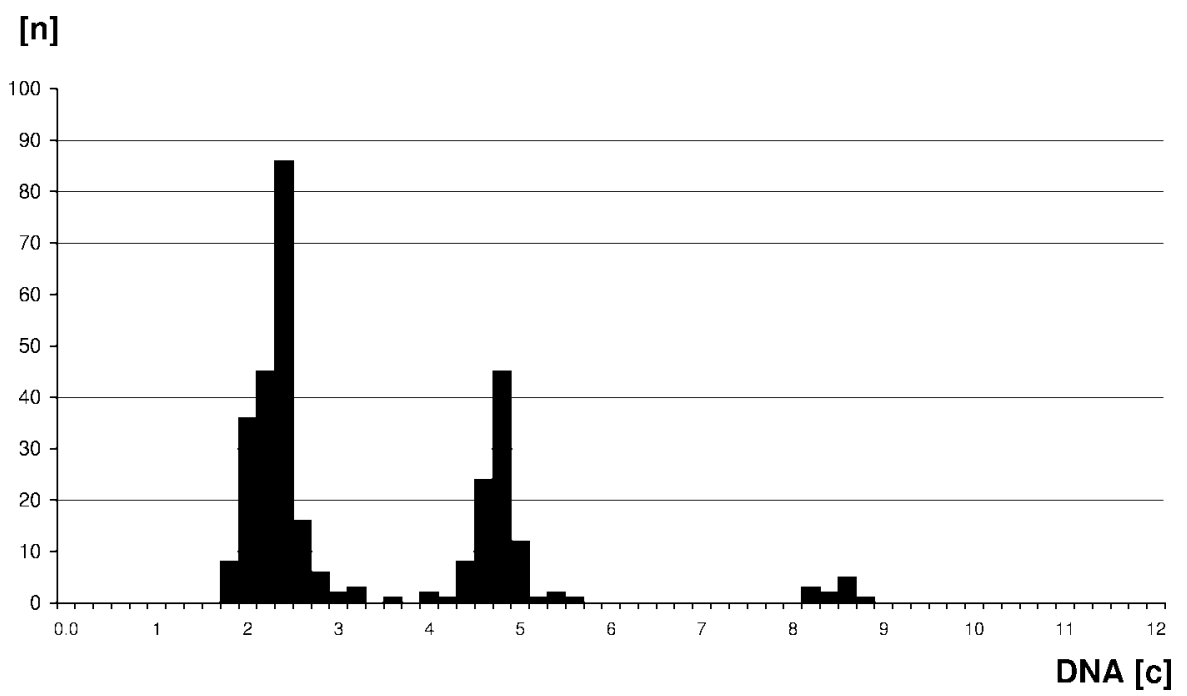

Fig. 4. DNA-histogram of a smear from a squamous cell carcinoma of the tongue. An abnormal stemline at $2.3 \mathrm{c}$ can be detected as one aspect of DNA-aneuploidy.

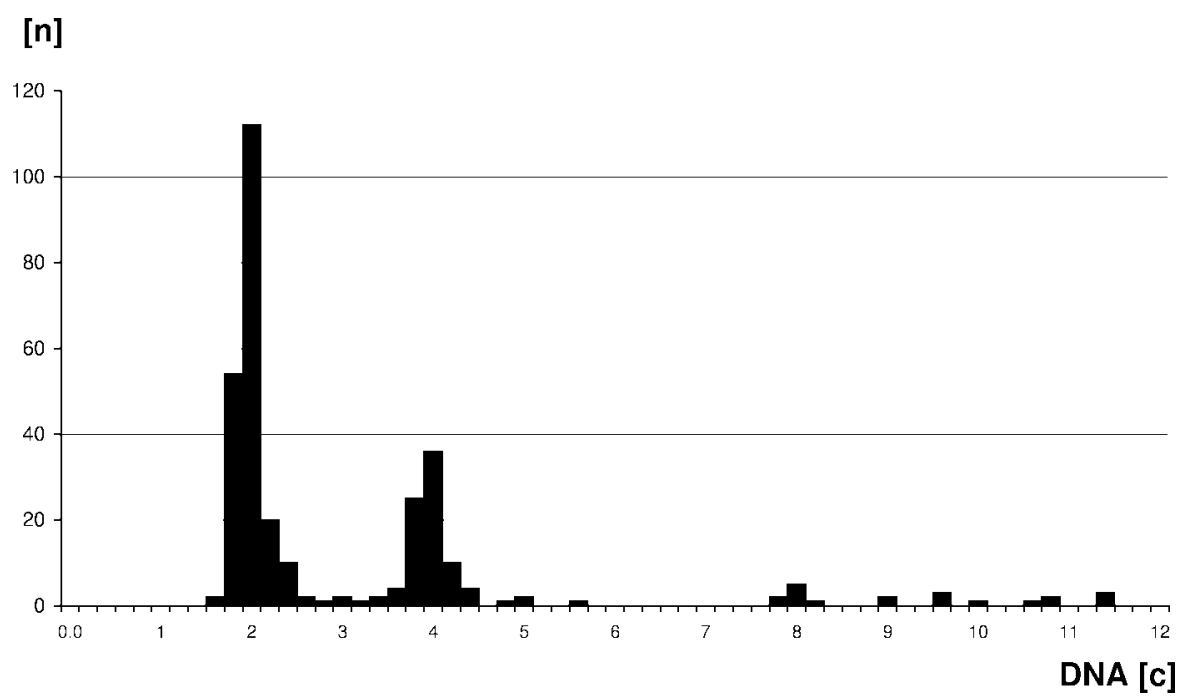

Fig. 5. DNA-histogram of a smear from a squamous cell carcinoma of the alveolar ridge. 12 cells with a DNA-content greater 9c (9cEE) can be detected as one aspect of DNA-aneuploidy.

Sensitivity of DNA-aneuploidy on oral smears for the detection of cancer cells was $96.4 \%$, specificity for the detection of non neoplastic cells $100 \%$, positive predictive value $100 \%$ and negative predictive value $99.0 \%$ (Table 4). The combination of both techniques increased the sensivity to $98.2 \%$, specificity to $100 \%$, positive predictive value to $100 \%$ and negative predictive value to $99.5 \%$ (Table 5).

Clinically four seemingly benign lesions were detected as malignant by cytology. In these cases a scalpel biopsy would not have been taken routinely, be- cause even for an experienced surgeon the clinical aspect was not suspicious for cancer.

\section{Discussion}

Although up to now surgical biopsy is the "Golden Standard" for diagnosing oral cancers, available information about the accuracy of biopsy histology is limited.

Sudbo et al. [46] reported that from 150 patients with histologically diagnosed oral epithelial dysplasias 
[n]

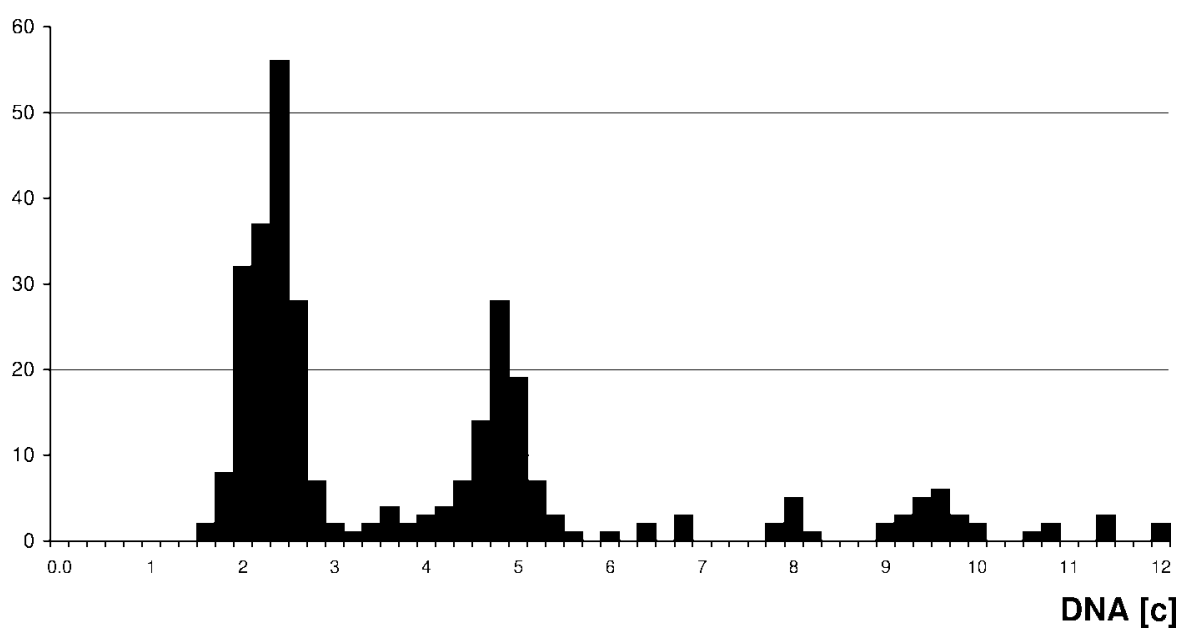

Fig. 6. DNA-histogram of a smear from a squamous cell carcinoma of the buccal mucosa. Different aspects of DNA-aneuploidy can be detected: abnormal stemlines at $2.4 \mathrm{c}, 4.8 \mathrm{c}$ and 29 cells greater $9 \mathrm{c}(9 \mathrm{cEE})$.

Table 3

Sensitivity and specifity of cytology versus histology $(n=$ 251 cases)

\begin{tabular}{llcc}
\hline \multirow{2}{*}{ Cytology } & \multicolumn{2}{c}{ Histology } \\
\cline { 3 - 4 } & & $\begin{array}{c}\text { Negative for } \\
\text { tumor cells }\end{array}$ & $\begin{array}{c}\text { Positive for } \\
\text { tumor cells }\end{array}$ \\
\hline Negative for & negative & 192 & 1 \\
tumor cells & doubtful & 2 & 2 \\
Positive for & suspicious & 0 & 8 \\
tumor cells & positive & 1 & 45 \\
\hline
\end{tabular}

Table 4

Sensitivity and specifity of DNA-cytometry versus histology ( $n=250^{*}$ cases)

\begin{tabular}{lcc}
\hline DNA-cytometry & \multicolumn{2}{c}{ Histology } \\
\cline { 2 - 3 } & $\begin{array}{c}\text { Negative for } \\
\text { tumor cells }\end{array}$ & $\begin{array}{c}\text { Positive for } \\
\text { tumor cells }\end{array}$ \\
\hline $\begin{array}{l}\text { DNA-non- } \\
\text { aneuploid }\end{array}$ & 195 & 2 \\
DNA- & 0 & 53 \\
aneuploid & & \\
* One case technically insufficient for DNA-cytometry.
\end{tabular}

more than 36 (24\%) patients developed a squamous cell carcinoma during the follow up, 105 were diploid, $20(13 \%)$ tetraploid and $25(17 \%)$ aneuploid at initial diagnosis. Three of 105 diploid cases (3\%), as opposed to 21 of 25 aneuploid cases $(84 \%)$ developed a carcinoma during follow-up (negative predictive value $97 \%$ for diploid lesions and positive predictive value $84 \%$ for the aneuploid lesions).
Table 5

Sensitivity and specifity of cytology and DNAcytometry versus histology ( $n=251$ cases)

\begin{tabular}{ccc}
\hline \multirow{2}{*}{$\begin{array}{c}\text { Cytology } \\
\text { DNA-cytometry }\end{array}$} & $\begin{array}{c}\text { Negative for } \\
\text { tumor cells }\end{array}$ & $\begin{array}{c}\text { Positive for } \\
\text { tumor cells }\end{array}$ \\
\cline { 2 - 3 } Negative for & 195 & 1 \\
tumor cells & & 55 \\
$\begin{array}{l}\text { Positive for } \\
\text { tumor cells }\end{array}$ & 0 & \\
\hline
\end{tabular}

Many papers were published on oral cytology during the period from 1950-1970. Sensitivity was about $87.3 \%$ (average from the literature of more than 1300 cases from 18 studies [25]) and revealed a range from $48 \%$ to $100 \%$. Sensitivity was about $99.1 \%$ with a range from $77.7-99.6 \%$ in more than 16420 cases from 7 studies [25]. These differences in diagnostic accuracy of cytology may be the reason for the fact that scalpel biopsy with histological assessment is currently the only accepted method for the diagnosis of oral lesions suspicious for malignancy. Although surgical biopsy up to now is the "golden standard" for identification, histogenetic typing and grading malignant lesions, available information about its diagnostic sensitivity, specifity and interobserver reproducibility is limited. However, Guinta et al. showed, that $2.5 \%$ of oral cancers were not correctly diagnosed on the initial biopsy [19], resulting in a sensitivity of only $97.5 \%$. Additionally, there are reports on patients whose initial scalpel biopsies were negative, but whose initial tu- 
Table 6

Prevalence and different aspects of DNA aneuploidy in oral brushings ( $n=53$ histologically proven squamous cell carcinomas)

\begin{tabular}{|c|c|c|c|c|c|c|c|c|}
\hline \multirow[t]{2}{*}{ Aspects of DNA aneuploidy } & \multicolumn{2}{|c|}{ Positive for tumor cells } & \multicolumn{2}{|c|}{ Suspicious for malignancy } & \multicolumn{2}{|c|}{ Doubtful } & \multicolumn{2}{|c|}{ Total } \\
\hline & $n=45$ & $(100 \%)$ & $n=6$ & $(100 \%)$ & $n=2$ & $(100 \%)$ & $n=53$ & $(100 \%)$ \\
\hline Abnormal stemline only & 2 & $4.4 \%$ & 2 & $33.3 \%$ & 1 & $50.0 \%$ & 5 & $9.4 \%$ \\
\hline One & & & 1 & & 1 & & & \\
\hline Two & & & & & & & & \\
\hline Multiple & 2 & & 1 & & & & & \\
\hline 9cEE only & 7 & $15.6 \%$ & 2 & $33.3 \%$ & 1 & $50.0 \%$ & 10 & $18.9 \%$ \\
\hline $1-3$ & & & 1 & & & & & \\
\hline $4-10$ & 3 & & 1 & & 1 & & & \\
\hline$>10$ & 4 & & & & & & & \\
\hline Abnormal stemline and $9 \mathrm{cEE}$ & 36 & $80.0 \%$ & 2 & $33.3 \%$ & & & 38 & $71.7 \%$ \\
\hline
\end{tabular}

mor cell positive smears subsequently prompted further biopsies that confirmed the presence of carcinomas $[22,40]$.

A potential explanation for the bad sensitivity could be that formerly the obtainment of cells was disadvantageously performed with a cotton tip or scraper. Today a brush with small bristles is used (see material and methods) increasing the number of collected cells [24]. The clinical advantages of exfoliative cytology are evident: non-invasive, relatively painless and fast obtainment. Every dentist can perform an oral brushing, which represents a low budget procedure (in Germany 40 Euro for both techniques), revealing high compliance (e.g., even when used repeatedly for monitoring; often patients are not inclined to repeated scalpel biopsies) and up to now no contradiction for brushing is known. We report here on a sensitivity of $98.2 \%$ and specifity of $100 \%$ of oral cytodiagnoses combined with DNA-cytometry. This represents better results as obtained by scalpel biopsy with histological assessment.

Ogden et al. [35] report that the sensitivity and specifity of DNA quantification has been $70 \%$ and $90 \%$, respectively, investigating oral smears from biopsy proven cancer. Brickley et al. [12] have tested the performance of a computer simulated neural network using image analysis trained to categorise normal, premalignant and malignant oral smears. The data were derived from the analysis of 348 intra-oral smears and included mean nuclear and mean cytoplasmic areas. They reported on a specificity of $82 \%$ and sensitivity of $76 \%$ concerning the differentiation between normal/non-dysplastic- and dysplastic/malignant mucosa.

The method of computer assisted cytological analysis (Oral CDx) of oral brush biopsy presented by Sciubba et al. [44] aims at the identification of squamous dysplasias of any degree together with carcinomas us- ing TV-image analysis and neural networks. It subjects all patients with oral dysplasia irrespective of their degree to scalpel biopsy although many of them do not reveal obligatory precancerous lesions. The method makes no use of the DNA-content of the exfoliated cells and reveals low specifity. Twenty-one percent of the resected lesions with cytologic atypias revealed benign histologic diagnoses and should not have been resected. Most likely these histologically benign lesions had euploid DNA-histograms. The method of Sciubba et al. thus represents a tool to substitute screening personal for identifying abnormal and atypical oral squamous cells on oral smears. Yet, it does not aim at a definite diagnosis concerning the presence or absence of malignancies, as ours does, which can compete with histological evaluation and is able to save scalpel biopsies.

A variable which influences the detection rate of DNA-aneuploidy is the number of cells measured. This study is based on at least 50, mostly on more than 300 abnormal epithelial cells and 30 reference cells per case. Previous studies from Ogden et al. [35] using static DNA-cytometry were based on only 50 randomly-selected cells for analysis.

\subsection{Algorithms for detection of DNA-aneuploidy}

A DNA-stemline in an abnormal histogram-position is supposed to be due to chromosomal aneuploidy and is thus often named a "DNA-aneuploid" stemline. Whereas cells belonging to a DNA-stemline are supposed to be cytogenetically identical proliferating cells, so called "rare events" with DNA-contents $>9 \mathrm{c}$ most likely represent non proliferating cells with different chromosomal aneuploidies and an abnormally high number of chromosomes [11]. In tissues revealing euploid polyploidisation like the oral mucosa (e.g., [6]) 
the $9 \mathrm{c}$ exceeding events should be applied because no cells exceeding that value occur in reactive, proliferating benign tissues. This marker was observed in $84.6 \%$ of the cytological materials of oral carcinomas. We disagree in this point with other authors [37] who have used the detection of cells with more than 5c DNAcontent as marker of DNA-aneuploidy in tissues that show euploid polyploidisation as the oral epithelium. Schulte et al. [43] have used $>5 \mathrm{c}$ DNA-content (5c exceeding events $[5 \mathrm{cEE}])$ as a parameter for the detection of malignancy with a sensitivity of $100 \%$, but they did not report on a tumor cell free (negative) control group. False positive results may occur using $5 \mathrm{cEE}$ for detection of DNA-aneuploidy.

We attribute our high prevalence of DNA-aneuploidy in tumor cells to a sufficient precision of nuclear DNA-measurements and to the application of two different algorithms to detect DNA-aneuploidy (abnormal stemlines and rare events $>9 \mathrm{c}$ ).

We therefore propose to look for more than one aspect of DNA-aneuploidy in histograms if a high detection rate is desired. Considering the results of carcinoma specimens the detection rate of malignant cells is $78.2 \%$ by using DNA-stemline-aneuploidy alone increasing to $96.4 \%$ by additional applying $9 \mathrm{cEE}$ as an other aspect of DNA-aneuploidy. 10 cases (18.9\%) were DNA-aneuploid by detection of rare events $>9 \mathrm{c}$ without abnormal stemlines (Table 4).

The results show that in future no DNA-cytometric assessment is necessary in cytologically "tumor cell negative" cases. It is advised to use DNA-image cytometry only in the case of epithelial dysplasias for the identification of the prospectively malignant ones and in tumor cell-positive diagnoses for quality assessment of the tumor diagnoses.

Not unmentioned should be the fact that nearly no comparable adjuvant diagnostic procedure has a higher level of standardization like DNA-image cytometry. This is documented by three published consensus reports on standardized diagnostic DNA-image cytometry of the European Society of Analytical Cellular Pathology (ESACP) [7,11,18,20] and the results of the "International Consensus Conference on the fight against Cervical Cancer" in Chicago, spring 2000 [50]. Furthermore, competence on DNA-image cytometry can be obtained online using ISDN or the Internet and the EUROQUANT server [21]. Thus combined oral cytology and DNA-image cytometry result in a clinical screening procedure for early detection of oral cancer with high diagnostic accuracy, low costs, high objectivity and good patients compliance.

\section{Conclusion}

Cytologic investigation of smears from macroscopically suspicious oral lesions is an easily practicable, cheap, quick, non-invasive, painless and accurate screening method that may help to reduce the occurrence of invasive and thus fatal squamous cell carcinomas. The application of DNA-image cytometry with DNA-aneuploidy as a marker for neoplastic transformation in oral smears secures the cytologic diagnosis of cancer. It furthermore helps to clarify the nature of morphologically doubtful squamous epithelial lesions like dysplasias or regenerative epithelium by identifying the obligatory precancerous or prospectively malignant ones and thus allowing an effective early therapy. The latter method is able to increase the sensitivity for the detection of malignant and specifity for benign cells in oral smears and thus decrease the rate of cytologically false negative or -positive diagnoses.

Cytologic and DNA-cytometric techniques may also be used to identify recurrent tumors after surgical treatment.

\section{Acknowledgements}

We wish to thank Mrs D. Bär for excellent technical assistance. Furthermore, we would like to express our thanks to Mrs B. Buckstegge and Mrs H. Müschenborn for the excellent preparation of slides.

\section{References}

[1] L.M. Abbey, G.E. Kaugars, J.C. Gunsolley, J.C. Burns, D.G. Page, J.A. Svirsky, E. Eisenberg, D.J. Krutchkoff and M. Cushing, Intraexaminer and interexaminer reliability in the diagnosis of oral epithelial dysplasia, Oral Surg. Oral Med. Oral Pathol. Oral Radiol. Endod. 80(2) (1995), 188-191.

[2] L.M. Abbey, G.E. Kaugars, J.C. Gunsolley, J.C. Burns, D.G. Page, J.A. Svirsky, E. Eisenberg and D.J. Krutchkoff, The effect of clinical information on the histopathologic diagnosis of oral epithelial dysplasia, Oral Surg. Oral Med. Oral Pathol. Oral Radiol. Endod. 85(1) (1998), 74-77.

[3] M. Abdel-Salam, B.H. Mayall, K. Chew, S. Silvermann, Jr. and J.S. Greenspan, Which oral lesions will become malignant? An image cytometric study, Oral Surg. Oral Med. Oral Pathol. 69 (1990), 345-350.

[4] M. Abdel-Salam, B.H. Mayall, L.S. Hansen, K. Chew and J.S. Greenspan, Nuclear DNA analysis of oral hyperplasia and dysplasia using image cytometry, J. Oral Pathol. 16 (1987), 431-35.

[5] M. Bibbo, Comprehensive Cytopathology, WB Saunders Company, Philadelphia, 1991, pp. 541-614. 
[6] S. Biesterfeld, L. Fuzesi, F. Härle and A. Böcking, DNAcytometric detection of euploid poyploidization in oral lichen ruber planus, Anal. Quant. Cytol. Histol. 131(1) (1991), 7-10.

[7] A. Böcking, F. Giroud and A. Reith, Consensus report of the European Society of Analytical Cellular Pathology task force on standardization of diagnostic DNA image cytometry, Anal. Quant. Cytol. Histol. 17(1) (1995), 1-7.

[8] A. Böcking, DNA-measurements. When and Why?, in: Compendium on Quality Assurance, Proficiency Testing and Workload Limitations in Clinical Cytology. Tutorials of Cytology, L. Wied, C.M. Keebler, D.L. Rosenthal, U. Schenck, T.M. Somrak and G.P. Vooijs eds, Chicago, Illinois, USA, 1995, pp. 170-188.

[9] A. Böcking and N. Freudenberg, Standardisierte Befunderstellung in der extragenitalen Zytologie, Pathologe 19 (1998), 235-236.

[10] A. Böcking and H. Motherby, Assessment of cervical dysplasia with DNA image cytometry, Pathologe 20(1) (1999), 25-33.

[11] A. Böcking, G. Haroske, A. Reith, F. Girod, P. Spieler and A.A. Gschwendtner, Fourth Updated ESACP Consensus Report on DNA Image Cytometry, Anal. Quant. Cytol. Histol. (2001), in process.

[12] M.R. Brickley, J.G. Cowpe and J.P. Shepherd, Performance of a computer simulated neural network trained to categorise normal, premalignant and malignant oral smears, J. Oral. Pathol. Med. 25 (1996), 424-428.

[13] R. Chatélain, T. Schunck, E.M. Schindler, A.E. Schindler and A. Böcking, Diagnosis of prospective malignancy in koilocytic dysplasia of the cervix with DNA-cytometry, J. Reprod. Med. 34 (1989), 505-510.

[14] R. Chatélain, A. Willms, S. Bisterfeld, W. Auffermann and A. Böcking, Automated Feulgen staining with a temperature controlled staining machine, Analyt. Quant. Cytol. Histol. 11 (1989), 211-217.

[15] R. Chatelain, B. Hoffmeister, F. Härle, A. Böcking and C. Mittermayer, DNA-grading of oral squamous carcinomas. A preliminary report, Int. J. Oral. Maxillofac. Surg. 18 (1989), 43-46.

[16] D. Doseva, K. Christov and K. Kristeva, DNA content in reactive hyperplasia, precancerosis and carcinomas of the oral cavity. A cytophotometric study, Acta Histochem. 75 (1984), 113-119.

[17] K. Feulgen and H. Rossenbeck, Mikroskopisch-chemischer Nachweis einer Nucleinsäure vom Typus des Thymonucleinsäure und die darauf beruhende elektive Färbung von Zellkernen in mikroskopischen Präparaten, Hoppe Seyler Z. Physiol. Chem. 135 (1924), 203-248.

[18] F. Giroud, G. Haroske, A. Reith and A. Böcking, 1997 ESACP consensus report on diagnostic DNA image cytometry. Part II: Specific recommendation for quality assurance. European Society for Analytical Cellular Pathology, Anal. Cell. Pathol. 17(4) (1998), 89-200.

[19] J. Guinta, I. Meyer and G. Shaklar, The accuracy of the oral biopsy in the diagnosis of cancer, Oral Surg. Oral Med. Oral Pathol. 28 (1969), 552-556.

[20] G. Haroske, F. Giroud, A. Reith and A. Böcking, 1997 ESACP consensus report on diagnostic DNA image cytometry. Part I: Basis considerations and recommendations for preparation, measurement and interpretation. European Society for Analytical Cellular Pathology, Anal. Cell. Pathol. 17(4) (1998), 189-200.

[21] G. Haroske, W. Meyer, M. Oberholzer, A. Böcking and K.D. Kunze, Competence on demand in DNA image cytometry, Pathol. Res. Pract. 196(5) (2000), 285-291.

[22] R.L. Hayes, G.W. Berg and W.L. Ross, Oral cytology: is value and is limitations, J. Am. Dent. Assoc. 79 (1969), 649-657.

[23] H.P. Howald and M. Kainz, Zentralregister des DÖSAK für Tumoren im Kiefer-Gesichtsbereich, 7. Projektbericht, Zentrales Tumorregister des DÖSAK Gießen, 1996.

[24] C.J. Jones, F.E. Pink, P.L. Sandow, C.M. Stewart, C.A. Migliorati and R.A. Baughman, The cytobrush cell collector in oral cytology, Oral. Surg. Oral. Med. Oral. Pathol. 77 (1994), 101-107.

[25] G.E. Kaugars, S. Silverman, Jr., A.K. Ray, D.G. Page, L.M. Burns and J.A. Svirsky, The use of exfoliative cytology for the early diagnosis of oral cancers: is there a role for it in education and private practice?, J. Cancer Educ. 13(2) (1998), 85-89.

[26] D. Kindermann and C.H. Hilgers, Glare-correction in DNA image cytometry, Anal. Cell. Pathol. 6 (1994), 165-180.

[27] L.G. Koss, Diagnostic Cytology and its Histopathologic Bases, 4th edn, Lippincott Company, Philadelphia, 1992, pp. 10821184.

[28] L.G. Koss, The Papanicolaou test for cervical cancer detection. Triumph and tragedy, JAMA 261(5) (1989), 737-743.

[29] H. Motherby, T. Marcy, M. Hecker, B. Ross, B. Nadjari, H. Auer, K.M. Müller, D. Häussinger, B.E. Strauer and A. Böcking, Static DNA cytometry as a diagnostic aid in effusion cytology: I. DNA aneuploidy for identification and differentiation of primary and secondary tumors of the serous membranes, Anal. Quant. Cytol. Histol. 20 (1998), 153-161.

[30] H. Motherby, B. Nadjari, T. Remmerbach, T. Marcy, N. Pomjanskaja, W. Müller, K. Knops, D. Häussinger, B.E. Strauer and A. Böcking, Static DNA cytometry as a diagnostic aid in effusion cytology: II. DNA aneuploidy for identification of neoplastic cells in equivocal effusions, Anal. Quant. Cytol. Histol. 20 (1998), 162-168.

[31] H.W. Müller, A. Böcking and H. Auer, TV Cytometer CM1 for computer aided tumor diagnosis, in: Compendium on the Computerized Cytology and Histology Laboratory. Tutorials in Cytology, L. Wied, P.H. Bartels, D.L. Rosenthal and U. Schenck eds, Chicago, Illinois, USA, 1994, pp. 376-387.

[32] B. Nadjari, H. Motherby, T. Pooschke, S. Pooschke, H.E. Gabbert, D. Simon, H.D. Roher, J. Feldkamp, L. Tharandt and A. Böcking, DNA aneuploidy as a specific marker of neoplastic cells in FNAB of the thyroid, Anal. Quant. Cytol. Histol. 21(6) (1999), 481-488.

[33] B. Nadjari, A. Kersten, B. Ross, H. Motherby, R. Krallmann, R. Sundmacher and A. Böcking, Cytologic and DNA cytometric diagnosis and therapy monitoring of squamous cell carcinoma in situ and malignant melanoma of the cornea and conjunctiva, Anal. Quant. Cytol. Histol. 21(5) (1999), 387-396.

[34] G.R. Ogden, J.G. Cowpe and M. Green, Cytobrush and wooden spatula for oral exfoliative cytology. A comparison, Acta Cytol. 36 (1992), 706-710. 
[35] G.R. Ogden, J.G. Cowpe, D.M. Chrisholm and E.B. Lane, DNA and keratin analysis of oral exfoliative cytology in the detection of oral cance, Eur. J. Cancer. B. 6 (1994), 405-408.

[36] S.L. Parker, T. Tong, S. Bolden and P.A. Wingo, Cancer statistics, 1997. CA, Cancer J. Clinicans 47 (1997), 5-27.

[37] W.L. Parry and G.P. Hemstreet, Cancer detection by quantitative fluorescence image analysis, J. Urol. 139 (1989), 270-274.

[38] H. Platz, R. Fries and M. Hudec, Prognosis of Oral Cavity Carcinomas, Hanser, Munich-Vienna, Germany, 1986.

[39] T. Saku and E. Sato, Prediction of malignant change in oral precancerous lesions by DNA cytofluorometry, J. Oral Pathol. 12 (1983), 90-102.

[40] H.C. Sandler, Veterans Administration coperative study of oral exfoliative cytology, Acta Cytol. 7 (1963), 180-182.

[41] R. Schimming, M. Hlawitschka, G. Haroske and U. Eckelt, Prognostic relevance of DNA image cytometry in oral cavity carcinomas, Anal. Quant. Cytol. Histol. 20(1) (1998), 43-51.

[42] D. Schön, J. Bertz and H. Hoffmeister, Bevölkerungsbezogene Krebsregister in der Bundesrepublik Deutschland, Robert Koch Institut Schriften 2 (1995), 374.

[43] E.K.W. Schulte, U. Joos, M. Kasper and H.M. Eckert, Cytological detection of epithelial dysplasia in the oral mucosa using Feulgen-DNA-image cytometry, Diagn. Cytopathol. 7 (1991), 436-441.
[44] J.J. Sciubba, Improving detection of precancerous and cancerous oral lesions. Computer assisted analysis of the oral brush biopsy. U.S. Collaborative OralCDx Study Group, J. Am. Dent. Assoc. 130(10) (1999), 1445-1457.

[45] P.M. Stell, G.D. Wood and M.H. Scott, Early oral cancer: Treatment by biopsy excision, Br. J. Oral. Surg. 20 (1982), 234-236.

[46] J. Sudbo, W. Kildal, B. Risberg, H.S. Koppang, H.E. Danielsen and A. Reith, DNA content as prognostic marker in patients with oral leukoplakia, N. Engl. J. Med., in press.

[47] K. Sugimachi, H. Ide, T. Okamura, H. Matsuura, M. Endo and K. Inokuchi, Cytophotometric DNA analysis of oral mucosa and submucosal carcinoma of esoephagus, Cancer $\mathbf{5 3}$ (1984), 2683-2687.

[48] J.C. Weir, W.D. Davenport and R.L. Scinner, A diagnostic and epidemiologic survey of 15,783 oral lesions, J. Am. Dent. Assoc. 115 (1987), 439-442.

[49] World Health Organization Collaborating Centre for Oral Precancerous Lesions, Definition of leukoplakia and related lesions: an aid to studies on oral precancer, Oral Surg. 46 (1978), 518-539.

[50] V. Zylka-Menhorn, DNA-Bild-Zytometrie international standardisiert, Deutsches Ärzteblatt 9719 (2000), 1280. 


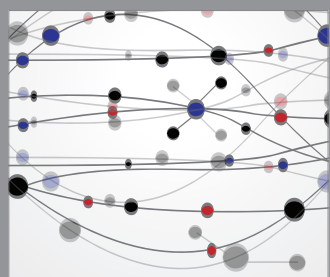

The Scientific World Journal
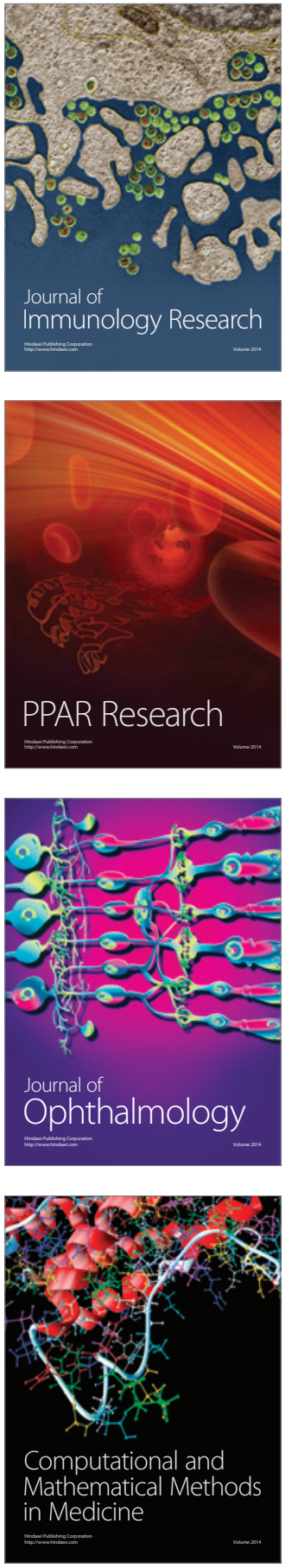

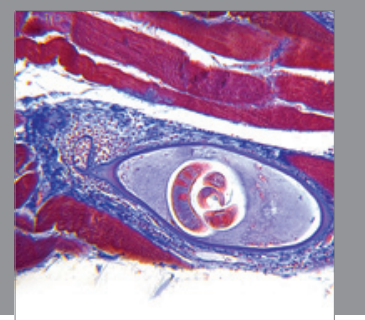

Gastroenterology

Research and Practice
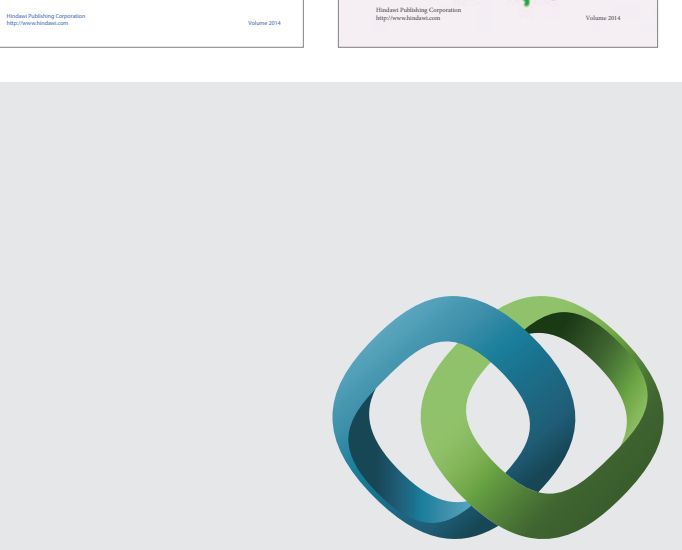

\section{Hindawi}

Submit your manuscripts at

http://www.hindawi.com
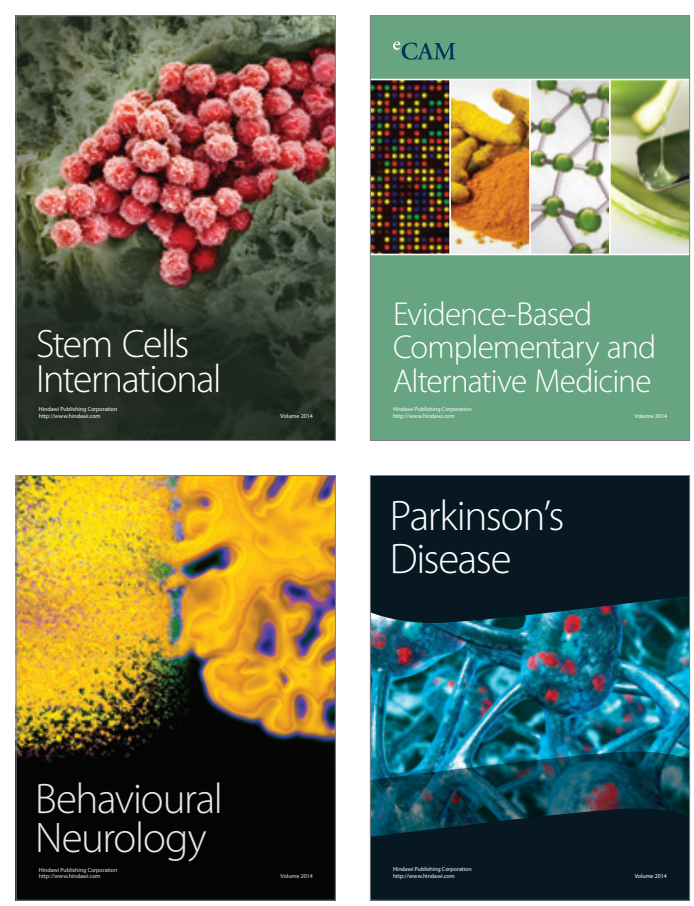

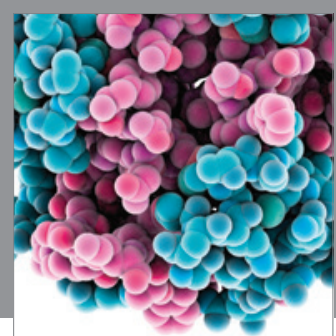

Journal of
Diabetes Research

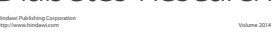

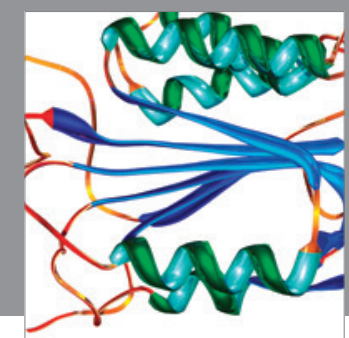

Disease Markers
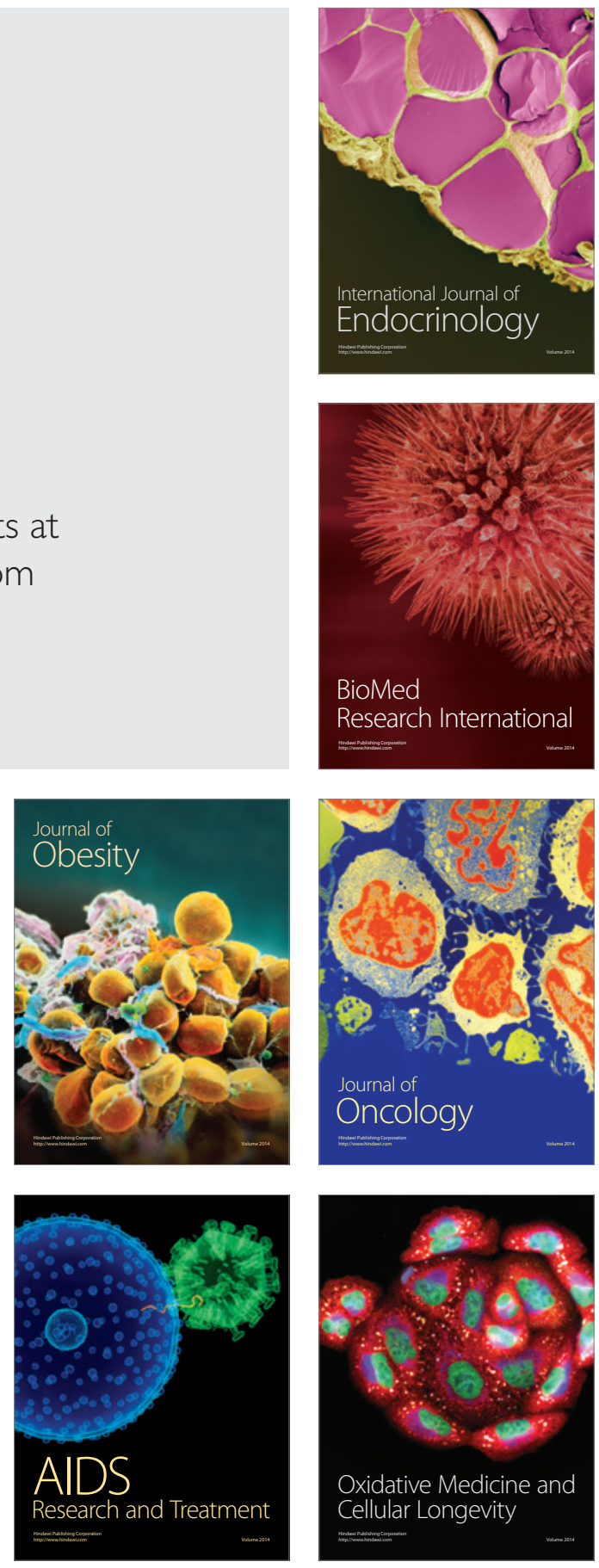